\title{
Possible impacts of a mutual currency on SCO's economic zone
}

\author{
Dr. Hadi Dolatabadi ${ }^{1}$ \\ ${ }^{1} \mathrm{PhD}$ in political science from Lumière, Lyon 2, University in France \\ Email : $\underline{\text { Hadi.dolatabadi@ut.ac.ir }}$
}

Mr. Mohammad Soltanian²

${ }^{2}$ Bachelor degree in Commercial Economics from Islamic Azad University of Khomeini Shahr in Isfahan, Iran

Emmy_rosum@yahoo.com

\begin{abstract}
The Shanghai Co-operation Organization (SCO), with security related priorities, including fighting against separatism, terrorism, and extremism has great potentials to be an economic tycoon in the international atmosphere. Being the most populated organization that ever existed, SCO as a free economic zone could provide possibilities for its members to compete with other unions and organizations all over the world. To do so, emerging a mutual currency between members could play a key role in SCO's rivalry with other players in the international markets. This paper is an endeavor to explain the challenges and opportunities for members by using SWOT analysis through both online and library sources to understand if moving into an economic zone, including a mutual currency could better off members and introduce the SCO as a unified monetary unit.
\end{abstract}

Keywords: Regional organizations, SCO's free trade zone, laissez faire policy, Fixed exchange rate, floating exchange rate

\section{Introduction}

As a union, with a look at their predecessor (European countries), SCO members need a tool in the international atmosphere that could help them to react to their rival's moves in the market. Taking a look at trade competition internationally, it could be seen that since the creation of the Euro, inside union trades for its members got easier and even a vast majority of needed goods and services preferred to be demanded from other members.

In this essay, emerging of a mutual currency between SCO members will be analyzed regarding to the fact that there are different expectations from this possible currency in the case of its fluctuations versus major currencies such as USD, GBP, CHF, JPY, EUR, and so on. On the other hand, similarities and differences of this mutual currency with Euro will be analyzed as to the strength point of members of this emerging economic zone.

It could be seen that there are two types of behavior that could be expected from SCO's possible currency. The first one is a fixed method to evaluate it to other currencies and the second one which obeys a floating method. Fixed exchange rate: A fixed exchange rate is a rate defined by the government or central bank, which defines the value of a currency in a certain amount of other currencies or gold. The purpose of a fixed exchange rate system is to keep a currency's value within a narrow band (Majaski, 2019). On the other hand, a floating exchange rate is a rate which would set by supply and demand of that currency in the market. In this case, all minor and major players in the market have their own effect on this process. This is in contrast to fixed method, in which the government entirely or predominantly determines the rate (Mitchell, 2019).

The other issue that will be considered is a shift from separate markets to a unified market, which all players have their chance to have their share from it. The consequences of such a phenomenon will affect all members in a way that they will gradually will shift toward producing goods and services which they have comparative advantage in them. Take for example, India based on is the territory which continues from north to south, could be very successful in agricultural products mainly because they can cultivate both cold and warm weather crops.

In following paragraphs, different scenarios and obstacles in the way of this mutual currency will be explained. Possible opportunities and weaknesses of moving toward a free economic zone for members will be analyzed as well. To do so, SWOT analysis had been employed to explain both positive and negative consequences of this mutual currency for SCO members. 


\section{Literature review:}

Although SCO is a young organization compared to many other international organizations and its foundation date backs to first years of 2000s. There are many studies related to its role and purpose which have done by other scholars. Take for example, some of those researches tried to define roles and advantages of their studied countries in the SCO (Yuan, 2010). Or in some others, the way that two main founders of SCO are managing this organization had discussed in some articles (Naarajärvi, 2012). As it is a new organization, sometimes SCO had been compared to other international organizations (Bhadrakumar, 2007). In many cases SCO had been studied as a security-related organization which backs to the basis of this organization (Lanteigne, 2006/2007) (or) (Facon, 2013) that focused on Russia's security strategy. Some scholars also concentrated on SCO's relation in its non- permanent member states or even countries outside the region (Brummer, 2007). Another basis of SCO is fighting against separatism which gathered initial members together and had been concerned in some researches (Katz, 2008) (or) (Hessbruegge, 2004) that focused on some separatist groups. Extremism is another subject for many scholars (Jacob Zenn and Kathleen Kuehnast, 2014), or (Khan, 2012) that emphasizes on lasting peace as well. Mutual affairs which all members' concern about it such as security of energy is another subject that had been researched by other scholars (OleOdgaarda\&JørgenDelmanb, 2014).

As it was expected, most of the researches related to the SCO are covering SCO's main goals which are fighting terrorism, separatism, and also extremism. Other subjects such as security of energy, relations with countries inside and outside the region, relations and cooperation with other regional and international organizations would only come after the initial purposes of formation of this organization.

Based on writer's research, dedicating a topic to a mutual currency in this region is a new subject and the writer couldn't find any topics related to mutual currency among SCO members or a regional currency in SCO zone.

\section{Definition of concepts:}

1: Major currencies: dominant currencies in the international business which are responsible for a vast majority of trades compared to currencies with less circulation in the market. US Dollar, Great Britain's Pound, Japanese Yen, Euro, Australian Dollar, Canadian Dollar, and Swiss Franc considered as major currencies all around the world.

\section{SCO's background:}

The Shanghai Cooperation Organization (SCO) is a permanent intergovernmental international organization, the creation of which was announced on 15 June 2001 in Shanghai (China) by the Republic of Kazakhstan, the People's Republic of China, the Kyrgyz Republic, the Russian Federation, the Republic of Tajikistan, and the Republic of Uzbekistan. It was preceded by the Shanghai Five mechanism (SCO, 2017).

On the one hand, this group of countries wanted to challenge America's influence in central Asia and on the other hand, these countries wanted to solve their border relation tensions among themselves and also confront terrorism, separatism, and extremism in central Asia. From an economic point of view, it could be claimed that SCO members believe in a future based on more powerful regional organizations with more emphasize on Asian or even African and Latin members at least in parallel with western order.

\section{SCO as a unified economic zone:}

The necessity of a mutual currency comes up when we look at SCO as an economic organization or a free trade zone among its members. It is an axiom that exchange- related costs will remove for retailers in this zone and traders would be active with less obstacles in business in this zone. On the other hand, countries could set their priority to provide their needed goods and services from other countries in this organization. It also paves the way to create a more compatible market for all members to try to export their goods and services outside the SCO trade zone. In other words, with a mutual currency all producers should try to reduce the final price of their goods and services to be able to compete with others in this area.

The other positive effect of this unified area and currency is that it allows all SCO members to move toward those goods and services that they have advantage in them, which means that in theory, all members could be better off after this effort compared to a situation that they produce many goods and services inside their territory.

There is no doubt that SCO needs its own economic plan on its way to a faster growth and development for its members. In this way, looking at EUR's pros and cons could help decision makers in this region to create their unique method. As EUR's decision makers defined their currency as a flexible rival vs other currencies such as the US dollar, they 
had to manage many verdicts for their major decisions while their main rival in the international business (USD) took advantage of a united policy. A notable difference between Eurozone and SCO is that in Europe most trades are between members. Trade in goods accounts for about three-quarters of total euro area external trade (European Central, 2019). While in China, as the biggest economic power of SCO main trade partners are:

\section{1: China}

1. United States: US $\$ 479.7$ billion (19.2\% of total Chinese exports)

2. Hong Kong: $\$ 303$ billion (12.1\%)

3. Japan: $\$ 147.2$ billion $(5.9 \%)$

4. South Korea: $\$ 109$ billion (4.4\%)

5. Vietnam: $\$ 84$ billion (3.4\%)

6. Germany: $\$ 77.9$ billion $(3.1 \%)$

7. India: $\$ 76.9$ billion $(3.1 \%)$

8. Netherlands: $\$ 73.1$ billion $(2.9 \%)$

9. United Kingdom: $\$ 57$ billion (2.3\%)

10. Singapore: $\$ 49.8$ billion (2\%)

(Workman, China's Top Trading Partners, 2019)

It could be seen that the most important SCO business partner for China is India, which only is responsible for just above 3 percent of Chinese exports.

These statistics for India, as the second populated country in the region (world) are:

\section{2: India:}

1. United States: US\$51.6 billion (16\% of total Indian exports)

2. United Arab Emirates: $\$ 29$ billion (9\%)

3. China: $\$ 16.4$ billion $(5.1 \%)$

4. Hong Kong: $\$ 13.2$ billion (4.1\%)

5. Singapore: $\$ 10.4$ billion (3.2\%)

6. United Kingdom: $\$ 9.8$ billion (3\%)

7. Germany: $\$ 9$ billion $(2.8 \%)$

8. Bangladesh: $\$ 8.8$ billion $(2.7 \%)$

9. Netherlands: $\$ 8.7$ billion $(2.7 \%)$

10. Nepal: $\$ 7.3$ billion (2.3\%)

(Workman, India's Top Trading Partners, 2019)

It could be seen that China as the most important partner among SCO members is only responsible for just above 5 per cent of India's exports.

These statistics for Russia are:

\section{3: Russia}

1. China: US $\$ 56$ billion (12.5\% of total Russian exports)

2. Netherlands: $\$ 43.5$ billion $(9.7 \%)$

3. Germany: $\$ 34.1$ billion $(7.6 \%)$

4. Belarus: $\$ 21.8$ billion $(4.9 \%)$

5. Turkey: $\$ 21.3$ billion $(4.8 \%)$

6. South Korea: $\$ 17.8$ billion (4\%)

7. Poland: $\$ 16.5$ billion $(3.7 \%)$

8. Italy: $\$ 16.4$ billion $(3.7 \%)$

9. Kazakhstan: $\$ 12.9$ billion $(2.9 \%)$

10. United States: $\$ 12.5$ billion $(2.8 \%)$

(Workman, Russia's Top Trading Partners, 2019)

Based on these statistics, it could be claimed that economic tycoons in SCO (China, India, and Russia) are not tied enough with other players (countries) in this economic zone.

One possible reason for that is the mutual comparative advantages among SCO members which makes other members to trade with other countries than SCO members.

Take for example. China's main imports compared to India's main imports.

\section{1: China}

1. Electrical machinery, equipment: US $\$ 521.5$ billion (24.4\% of total imports)

2. Mineral fuels including oil: $\$ 347.8$ billion (16.3\%)

3. Machinery including computers: $\$ 202.3$ billion $(9.5 \%)$

4. Ores, slag, ash: $\$ 135.9$ billion $(6.4 \%)$

5. Optical, technical, medical apparatus: $\$ 102.5$ billion $(4.8 \%)$

6. Vehicles: $\$ 81.5$ billion $(3.8 \%)$ 
7. Plastics, plastic articles: $\$ 74.9$ billion $(3.5 \%)$

8. Organic chemicals: $\$ 67.4$ billion (3.2\%)

9. Gems, precious metals: $\$ 62$ billion $(2.9 \%)$

10. Copper: $\$ 47.6$ billion $(2.2 \%)$

(Workman, China's Top 10 Imports, 2019)

\section{2: India:}

1. Mineral fuels including oil: US $\$ 168.6$ billion (33.2\% of total imports)

2. Gems, precious metals: $\$ 65$ billion $(12.8 \%)$

3. Electrical machinery, equipment: $\$ 52.4$ billion $(10.3 \%)$

4. Machinery including computers: $\$ 43.2$ billion $(8.5 \%)$

5. Organic chemicals: $\$ 22.6$ billion $(4.4 \%)$

6. Plastics, plastic articles: $\$ 15.2$ billion $(3 \%)$

7. Iron, steel: $\$ 12$ billion (2.4\%)

8. Animal/vegetable fats, oils, waxes: $\$ 10.2$ billion (2\%)

9. Optical, technical, medical apparatus: $\$ 9.5$ billion (1.9\%)

10. Inorganic chemicals: $\$ 7.3$ billion $(1.4 \%)$

(Workman, India's Top 10 Imports, 2019)

It could be seen that mineral fuels and raw materials have a huge portion in both countries import basket. Taking a look at both countries, it could be understood that neither of them is able to provide these materials in the way that meet their domestic demand, so it is natural that each one of them starts importing their needed materials from outside this economic zone (SCO).

\section{A CRITICAL DECISION:}

Now, that the importance of a mutual currency is clear, members should face a challenge related to the nature (behavior) of this currency. The question is that: how this new currency should behave in the international atmosphere in its relation to other currencies specially, major currencies (USD, EUR, JPY, GBP, CHF, AUD and CAD). China, as the economic leader of this organization for sure prefers the fixed method that defines this currency at a specific exchange rate with other currencies.

On the other hand, approximately all other members prefer a floating exchange rate which allows them to benefit of different economic fluctuations in different exchange rates.

Take for example, Russia sees the SCO as an anti-NATO organization that could help Russia when is needed. On the other hand, China looks at SCO something more than just a security- related organization. In the case of floating exchange rate, based on the population existing in the central Asia, it could be claimed that a new and strong currency will appear that could define itself as a new major currency pair with USD on the one hand, and also a strong cross pair currency vs any other currencies which are circulating in a large scale in the international market. SCO's population, in this case will immediately show its consequences in the market and sets this currency amongst the most traded currencies all around the world. With the advantage of acceptability in both domestic and regional trades, it will immediately show itself as a rival for EUR as the only regional currency that is able to compete with it in the case of acceptability and velocity.

In the second scenario, which this region uses a fixed method for its exchange rate, SCO's potential to get involved with markets outside the region is more highlighted.

In following paragraphs, both scenarios will be analyzed through SWOT analysis.

\section{SWOT ANALYSIS:}

1: Strengths: Let's take a look at the positive effects of a mutual currency. If a mutual currency be accepted by all members, it could be seen that goods and services in the SCO zone will be cheaper for members and they will try to provide their needed goods and services from other members. The velocity of money will be higher as a result of an active market among members and probably more job opportunities could be seen in this economic zone because final goods and services could be economical options for customers outside this economic zone. (In this case, it is an axiom that countries with cheaper labor force and technology to export have more chance to lead the market in this area. China is a good example). In an open market situation among members, it is more easy to create job opportunities for skilled workers where they can move freely inside the economic zone in order to get employed where needed or create their own businesses regarding the fact that many production factors such as row materials and skilled and unskilled workers could be fined easily by small companies or even individuals.

Free circulation of money (capital), is another advantage of such a free market that uses a mutual currency.

When a business is more lucrative in one of members, it could be expected that capital and labor concentrate on that region

The second scenario is a floating exchange rate which allows countries with a higher level of technology needed 
to bring their material from outside the zone in the times that the exchange rate is high in favor of SCO's currency. (Russia is a good example that can benefit different exchange rates to maximize its benefit from trade with countries outside this economic zone).

2: Weaknesses: unfortunately, there is a problem with SCO members in the case of their economic advantages which make them cover mutual parts of the economy instead of covering different parts. Take for example, cheap work force in both India and China or gas production between Iran and Russia. Challenges for some members as a result of labor immigration to their territories. It is because that if workers find working in another country is more lucrative based on their expert, so they will move to that country or place to find a better and stronger economic lifestyle. It means that many sectors should get ready to give service and facilities to these newly added citizens. Providing more food and water sources will be a serious challenge for those states.

From a security point of view, it will be harder to detect illegal groups financial trades and resources.

3: Opportunities: As long as the trade between members is more lucrative for both sides with their mutual currency, more utility, job opportunity, and bigger market for everyone could be assumed. In this market, more populated countries such as China and India could provide both markets and job opportunities for their companies and labors. With a mutual currency, countries, companies and individuals will move toward their comparative advantages which will lead to specialized production on the one hand, and mass production on the other hand. With a fixed exchange rate in a situation that imports of goods and services from SCO members is more economical compared to other places, governments can create more job opportunities for citizens in the region, also SCO's workforce could immigrate to other countries to gain more lucrative or available jobs. Using a mutual currency is also an opportunity for two crowded members (China and India) avoid possible tensions from under rated currency values which will lead to a unified payment system and standard of living for workforce in long term.

4: Threats: For weaker countries which are not able to compete with cheap labors from other countries and are not able to provide a descent technology to export, unemployment is a natural result of using a mutual currency and moving toward a unified economic zone. Comparing between the agricultural sector in India and Mongolia is a good example in which Indian agricultural products with cheaper prices could destroy locals in Mongolia which are active in this section. The other issue is that in a situation that artificial intelligence is shrinking job opportunities, especially in developed countries, SCO members could face a problem with their unemployed citizens which could not find job opportunities inside and outside the region.

\section{Findings:}

Emerging an economic zone and using a mutual currency between SCO members could be analyzed in two ways. The way the it impacts countries in this organization and the way that impacts international business.

Although main founders of this organization look ready to compete in the international atmosphere, but countries with weaker economy such as Iran and Kyrgyzstan should adapt their economy to a situation that their industries get ready to compete with other members when import tariffs are such low that other countries could have more chances than their domestic industries. On the other hand, China, Russia, and India are already able to cover many goods and services in a large scale based on their advantage in the labor force and the technology that makes mass production possible for them. This situation is a negative entropy in the process of the emerging an economic zone that could compete with its rivals such as the Eurozone.

Using a mutual currency by the most populated organization in the world could affect the international atmosphere and rearrange major currencies in the international business. USD, EUR, JPY, CHF, GBP and other important currencies such as CAD and AUD are going to get affected by the emerging a new rival in the global market. Emerging a free trade zone beside using a mutual currency could change the behavior of SCO members in the international market as they may prefer to provide their needed goods and services from other members than countries or organizations outside their trade zone. For example, Iran and Russia as natural gas suppliers could gain bigger shares in India and China's energy market rather than Australia and Qatar that are currently more active in this region.

\section{Conclusions}

All in all, using a mutual currency with any possible nature (fixed or floating) in the case of exchange rate, could provide more opportunities in the market to enjoy the benefit of a larger market inside the SCO zone on the one hand, and providing export and import opportunities for industries and individuals on the other hand. This movement could lead to the emerge of an Asian developing political and economic tycoon which can challenge a unipolar or bipolar world order based on its large market and powerful currency. Like any other actions in the market, using a mutual currency has its own disadvantages and could pave the way for terrorist groups and separatists to provide financial sources because that currency will be used for both national and international trades. Using a unified monetary system in the case of trade with outside of the union will lead to a higher velocity for this currency because it makes countries, organization, companies and even 
individuals convert their money to this newly defined currency. Taking a look at both positive and negative points, it seems that a unified economic zone followed was the policy of using a mutual currency will challenge other popular exchange pairs and dominant currencies in the international atmosphere. It also will lead to a unified monetary policy among members because interest rates determined by central banks of any of these countries count not pay less or more to attract foreign FDI from other members. Although different economic modules, same comparative advantages and many international tensions such as 11 September and war between Afghanistan and USA had negative effects on this organization, but creation of a free trade zone and a mutual currency for this region could play its role as a factor that could make SCO members able to compete with other economic unions all around the world. Generally, the writer believes that the advantages of a mutual currency outweigh the disadvantages and will allow SCO members to act more effectively in the international atmosphere. Moreover, based on the possibilities in the case of each method of exchange rate, the writer believes that fixed exchange rate could make SCO members able to compete with major players in the international atmosphere.

\section{References}

[1] Qushimov, B., Ganiev, I. M., Rustamova, I., Haitov, B., \& Islam, K. R. (2007). Land degradation by agricultural activities in Central Asia. Climate Change and Terrestrial Carbon Sequestration in Central Asia; Lal, R., Suleimenov, M., Stewart, BA, Hansen, DO, Doraiswamy, P., Eds, 137-146.

[2] Sanaev, G., Kim, K. R., Hasanov, S., \& Ganiev, I. (2015). Review of postharvest aspects of fruits and vegetables subsector in Uzbekistan. Connecting local and global food for sustainable solutions in public food procurement, 14, 557.

[3] Hamzaev, A. X., Astanakulov, T. E., Ganiev, I. M., Ibragimov, G. A., Oripov, M. A., \& Islam, K. R. (2007). Cover crops impacts on irrigated soil quality and potato production in Uzbekistan. Climate Change and Terrestrial Carbon Sequestration in Central Asia, 349.

[4] Ganiev, I., Sanaev, G., \& Pardaev, K. (2018). Career expectations of undergraduate and graduate students at agricultural universities in Uzbekistan (No. 179). Discussion Paper, Leibniz Institute of Agricultural Development in Transition Economies.

[5] Stirzaker, RJ (2003). When to turn the water off: scheduling micro-irrigation with a wetting front detector. Irrigation Science, 22 (3-4). Pp. 177-185.

[6] Hutchinson, PA, Stirzaker, RJ (2000) A new method and device for scheduling irrigation. Irrigation Association of Australia, May 23-25, 2000 National Conference. Pp. 584-592.

[7] Murodov Otabek Ulugbekovich, Kattayev Bobir Sobirovich, Saylixanova Maftuna Komiljonovna, \& Ibodov Islom Nizomiy o`g`li. (2020). Smart irrigation of agricultural crops. Middle European Scientific Bulletin,3, 1-3. https://doi.org/10.47494/mesb.2020.3.16

[8] Otamurodova, M. . (2020). Scientific researches on the journalism esp in foreign universities and in Uzbekistan journalism and mass communication university. Middle European Scientific Bulletin, 3, 7-9. https://doi.org/10.47494/mesb.2020.3.18 